\title{
MODELING AND OPERATIONAL ANALYSIS OF AN AUTOMOTIVE SHOCK ABSORBER WITH A TUNED MASS DAMPER
}

\author{
Marian SIKORA* \\ *BWI Poland Technologies sp. z 0.0., ul. Podgórki Tynieckie 2, 30-399 Kraków, Poland \\ marian.sikora@bwigroup.com
}

received 21 June 2017, revised 26 September 2018, accepted 28 September 2018

\begin{abstract}
Recently, the topic of energy dissipation efficiency of vehicle suspension dampers has become a research and engineering problem due to structural requirements of vehicle manufacturers and the introduction of electric/hybrid cars. By principle, any disturbances in the damping force generation process translate into pressure fluctuations to be then transferred to the body of the vehicle. The effect known as rattling within the damper engineering community is perceived as detrimental to ride comfort. To improve the performance of a vehicle damper several methods can be devised and used. One approach is to optimize the settings of the valves in the damper. The approach, however, often influences the force output of the damper. Another technique involves the application of add-on systems. One such system is the tuned mass damper concept originally developed by Frahm for structural engineering applications. In the paper the author proposes a damper concept equipped with an external/internal tuned mass damper component for improving the dynamic characteristics of vehicle dampers. The author presents modeling details followed by simulations of the damper with the tuned mass damper concept subjected to oscillatory inputs, and a critical analysis of the presented results.
\end{abstract}

Key words: Vehicle Damper, Tuned Mass Damper, Rattle Noise, Vehicle Suspension, Automotive

\section{INTRODUCTION}

Nowadays a vehicle suspension of a passenger car is charged with a set of various requirements (Dixon, 2007). It provides the support for the body of the car. It contributes to the dynamic behavior of the vehicle, and is highly important from the safety point of view. The suspension's specific characteristics and configurations determine the so-called ride and comfort characteristics of the vehicle.

Recent trends in the vehicle suspension design have generated various engineering and research challenges. First, vehicle OEMs (Original Equipment Manufacturers) have imposed higher structural stiffness requirements on the suspension. Second, the entry and expansion of hybrid and electric vehicles have made all sources of noise and vibrations in the cars easier to identify and recognize. In that aspect the ability of a vehicle shock absorber or a suspension damper to dissipate the energy has been emphasized and focused on in the development process.

From the NVH (Noise, Vibration, Harshness) standpoint the suspension yields acoustic impression. This can be analyzed using frequency-domain or time-domain methods or both (Kruse, 2002; Kruse; 2008;). The so-called harshness is perceived within the frequency range from $30-100 \mathrm{~Hz}$. A typical hydraulic hum/noise becomes evident at frequencies above $100 \mathrm{~Hz}$. The noise is due to the flow of oil through small restriction holes in the valves. The noise and flow-induced vibrations are transferred through the damper-top mount assembly to the body of the car to be then perceived by the vehicle occupants as the car's comfort degradation. The transient phenomena are difficult to measure, characterize and model. They can be classified by the location at which they are generated, the root cause and the transfer path (Kruse, 2002).
The transient phenomena in the dampers can be handled either through modifications in the valves or through specific add-on systems. The tuned mass damper (TMD) invention by Frahm in 1911 is such a concept. Its operating principle is simple. The eigen-frequency of the tuned mass damper device is tuned to be equal to specific (unwanted) frequencies in a vibratory plant. The effect is a significant reduction of the vibrations amplitude at that frequency with a relatively lightweight component.

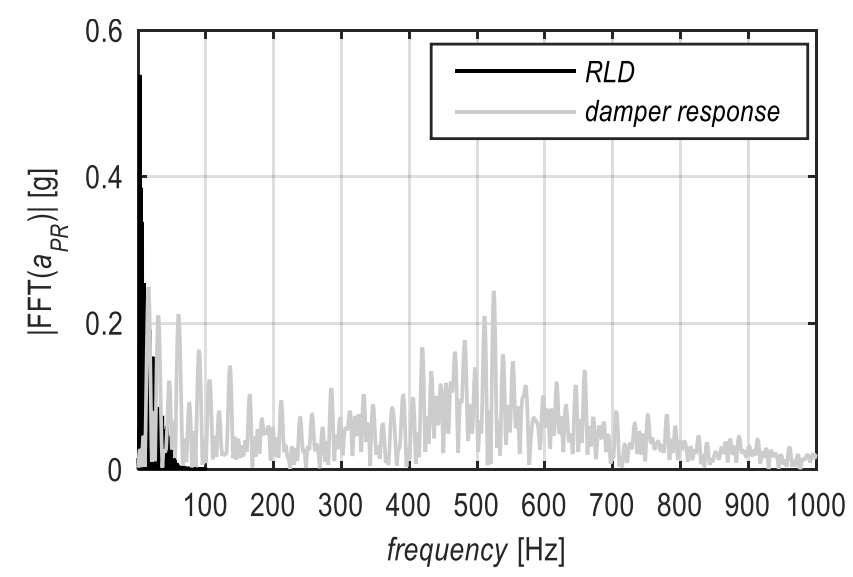

Fig. 1. Frequency spectrum of a typical road excitation profile (RLD) and recorded damper response; the frequency range of the excitation is much lower than the damper's

The tuned mass damper, however, eliminates the particular component from the frequency spectrum, yet introduces two additional peaks of smaller amplitude in it. That remains one major application issue of this system especially whenever a need 
to remove vibrations caused by harmonic excitations arises. In the investigated case the road input frequency (RLD) is much lower than frequency of the system (see Fig.1). It eliminates the potential risk of resonance. The concept has been patented for use in vehicle dampers (Trintignac, 1982; Shimizu, 1987; Gehrlich, 1992; Kohlmeier, 1992; Bayer, 1993; Tsuruta, 1999;), however, no attempts to model such vehicle damper-TMD systems are available in available literature sources.

In this paper the author presents the results of a numerical study on a lumped parameter model of a hydraulic double-tube damper featuring the tuned mass damper component. The response of the hybrid damper subjected to oscillatory inputs is presented and followed by a discussion of the obtained data. An attempt to characterize the potential improvements in the performance of the damper due to the new concept has been undertaken, too.

\section{DAMPER MODELING}

In this section the author presents a lumped parameter model of a vehicle suspension damper extended for use with a tuned mass damper concept device. The author analyses the key phenomena occurring inside the damper and highlights fundamental relationships between them.

A hydraulic damper is a complex device to model. A goodquality model for use across a wide frequency range of the excitation inputs should copy not only the processes accompanying the force generation process but also the resulting vibrations of the valves, compressibility of the oil-air emulsion, friction, etc. In that aspect the models of Lang and Duym remain well-known benchmark models (Lang, 1977; Duym, 1997). Notable research studies include the extension of the original models towards higher frequencies (Czop, 2011; Benaziz et al., 2013), and improvements in modelling of the shims stiffness in the valves (Czop, 2009; Farjoud, 2012).

The model that is presented in the current section represents the testing conditions of a damper in a lab - see Fig. 2. In the illustration the piston rod is attached to a flexible top mount-like assembly. The outer cylinder is driven by the prescribed displacement input of the MTS exciter.

Briefly, the double-tube damper model incorporates a system of four spring-loaded check valves as shown in Fig.3. The tube is driven by the prescribed displacement input $x_{e}$. The piston rod of the cross-section area $A_{r}$ is attached to a flexible top mount; the resulting displacement (acceleration) is then $x_{p r}\left(a_{p r}\right)$. The piston cross-section area is $A_{c}$. The piston rod mass is $m_{p r}$, and the top mount is best characterized by the stiffness ratio $k_{p r}$ and the damping coefficient $C_{p r}$. As the tube is moved upward, the fluid flow is forced through the valves in the piston. The flow rate through the piston valve compression disc stack is $Q_{r i}$ and the flow rate through the piston orifice from the compression (lower) chamber to the rebound (upper) chamber is then $Q_{r n}$. Similarly, the flow rate through the base (foot) valve compression disc stack is $Q_{c c}$ and the base valve orifice into the reservoir is referred to as $Q_{c n}$. The pressure in the compression chamber is $P_{c o m p}$. Accordingly, in the downward motion of the tube the fluid flows via the piston valves; the flow rate through the rebound disc stack is Qrc and the flow rate through the piston orifice is also $Q_{r n}$. Accordingly, the flow rate through the rebound chamber into the compression chamber and through the base valve intake disc is $Q_{c i}$ and the flow rate through the base valve orifice $Q_{c n}$ (from the reservoir volume into the compression chamber). The pressure in the rebound chamber is $P$ reb.

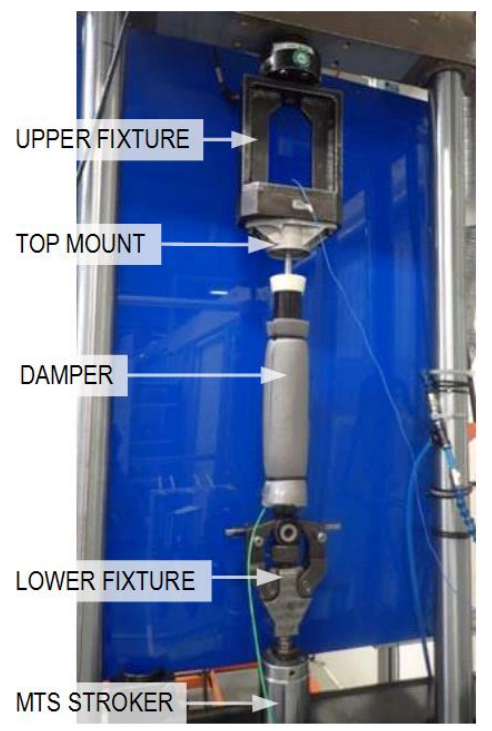

Fig. 2. Exemplary laboratory test setup of a damper

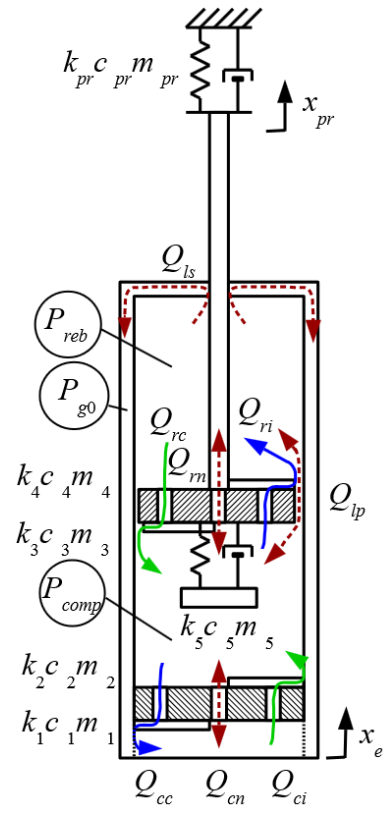

Fig. 3. Damper model layout

The oil in the damper is Newtonian and slightly compressible. It is characterized by the bulk modulus $\underline{\beta}$, the density $\rho$ and the dynamic viscosity $\mu$.

The dynamics of the valves is modelled by considering the motion of the discs as that of one degree of freedom (1DOF) system as illustrated in Fig. 4. As there are four sets of check valves (two in the piston and two in the base) the valves themselves are numbered are follows: (1) is the compression stack (in the base valve), (2) denotes the (rebound) intake disc in the base valve; (3) refers to the (piston) rebound discs stack; and (4) corresponds to the piston compression valve. Each valve can be characterized by the mass $m_{i}$, the stiffness ratio $k_{\text {i }}$ and the damping coefficient $c_{i}, i=1, \ldots, 4$. By balancing the forces acting on the $i$ th 
disc the following relationships can be deduced:

$F_{m i}+F_{c i}+F_{k i}+F_{K c i}=F_{v i}+F_{\Delta P i}+F_{M i}-F_{s p i}$,

where: $F_{m i}$ is inertia force, $F_{c i}$ is (viscous) damping force, $F_{k i}$ is spring force on the ith valve. The contact force $F_{K c i}$ is modelled as an additional spring whose stiffness ratio is $k_{c i}$. In the model a thin layer of oil is assumed between the contacting surfaces. To move apart two parallel surface filled with oil an additional force is required to pump the oil. This additional force is the stiction force $F_{v i}$ of the following form (Ezzat Khalifa and XinLiu 1998):

$F_{v i}=\frac{3 \pi \mu}{2 x_{i}^{3}} \frac{d x_{i}}{d t} R_{i}^{4}\left(1-X_{A i}^{4}+\frac{1-2 X_{A i}^{2}+X_{A i}^{4}}{\ln X_{A i}}\right)$,

The stiction force can be observed in all situations where the structure moves perpendicularly to the surface of the liquid. It depend on the oil viscosity, the hydraulic radius $R_{i}$ and the ratio $X_{A i}^{2}=1+A_{\text {contact }} / A_{\text {presure acting_area }}$ relating the contact area and the area on which fluid pressures act, respectively. The stiction force is proportional to the velocity and decreases rapidly with the increasing distance $x$.
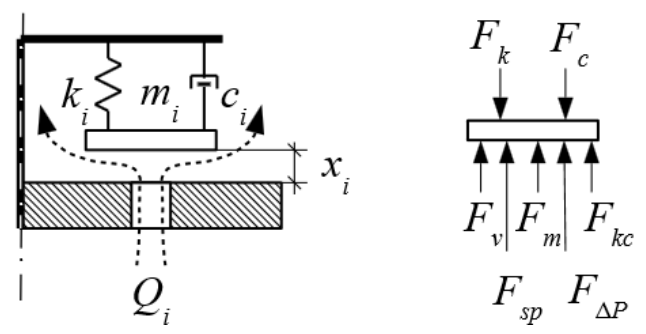

Fig. 4. Valve model and force diagram

The valves open once the generated force $F_{\triangle P i}$ exceeds the cracking pressure $\Delta P_{i}$ acting on the area $A_{v i}$. The force $F_{M i}$ accounts for the momentum change of the fluid. The force depends on the fluid density, the volumetric flow rate though valve $Q_{k}\left(Q_{c c}\right.$, $\left.Q_{c i}, Q_{c n}, Q_{r c}, Q_{r i}, Q_{r n}\right)$, the flow cross-section area Ain_i. Preloading the disc stack generates the preload force $F_{s p \_i}$ to prevent the valve from leaking and delay its opening. Then, by incorporating the lift acceleration $x_{u}$ the motion of the ith valve can be described as follows:

$m_{i}\left(\ddot{x}_{i}-\ddot{x}_{u}\right)+c_{i} \dot{x}_{i}+k_{i} x_{i}+\left\{\begin{array}{cc}-k_{c i} x_{i}, & x_{i}<0 \\ 0, & x_{i}>0\end{array}\right\}=F_{v i}+$

$\Delta P_{i} A_{v i}+C_{f i} \rho \frac{Q_{i}^{2}}{A_{\text {in }_{-} i}}-F_{s p_{-} i}$

where: $Q_{i}\left(Q_{c c}, Q_{c i}, Q_{r c}, Q_{r i}\right)$. In the model the cylinder tube radial expansion due to pressure is incorporated to calculate the effective compressibility $\beta_{1}$ :

$$
\beta_{1}=\beta+\frac{D}{E s},
$$

where: $D$ is the cylinder diameter, $s$ refers to wall thickness and $E$ denotes the steel Young's modulus. The flow rates through the valves are modelled by means of the modified Bernoulli equation:

$Q_{k}=C_{D k} A_{k} \sqrt{\frac{2 \Delta P_{k}}{\rho}}$

where: $C_{D k}$ - dynamic discharge coefficient, $A_{k}$ - cross-section area of the valve's outlet. Next, the leakage flows $\left(Q_{l p}, Q_{l s}\right)$ between the rod and the rod guide as well as the cylinder and the piston, respectively, can be described using the laminar flow relationship:
$Q_{l p}=\left(\frac{\left(P_{r e b}-P_{c o m p}\right) b_{p}^{3}}{12 \mu l_{p}} \pm \frac{\left(\dot{x}_{e}-\dot{x}_{p r}\right) b_{p}}{2}\right) W_{p}$

$Q_{l s}=\left(\frac{\left(P_{r e b}-P_{g 0}\right) b_{r}^{3}}{12 \mu l_{r}} \pm \frac{\left(\dot{x}_{e}-\dot{x}_{p r}\right) b_{r}}{2}\right) W_{r}$,

where: $b_{p}, b_{r}$ are the clearances between the piston and the cylinder and the piston rod and the rod guide, respectively, $I_{p}, I_{r}$ denote the leakage channel lengths, $W_{p}=\pi D_{p}$ accounts for the channel width at the circumference $D_{p}$, and $W_{r}=\pi D_{r}$ accounts for the channel width at the circumference $D_{r}$. The signs in equations 6 and 7 depend on the local coordinate system respective orientations.

Then, considering flow balance leads to the following relationship:

$\beta_{1} A_{c} L_{c} \dot{P}_{c o m p}=Q_{r c}+Q_{r n}-Q_{r i}-Q_{c c}+Q_{c n}+Q_{c i}+$
$Q_{l p}+A_{c}\left(\dot{x}_{e}-\dot{x}_{p r}\right)$.

Accordingly, the rebound pressure $P_{\text {reb }}$ can be calculated as:

$\beta_{1} A_{r} L_{r} \dot{P}_{r e b}=Q_{r i}-Q_{r n}-Q_{r c}-Q_{l p}-Q_{l s}-$ $A_{r}\left(\dot{x}_{e}-\dot{x}_{p r}\right)$,

where: $L_{c}$ is the length of the compression chamber, $L_{r}$ is the length of the rebound chamber.

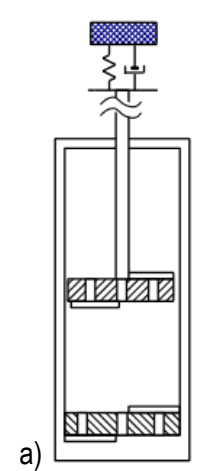

a)

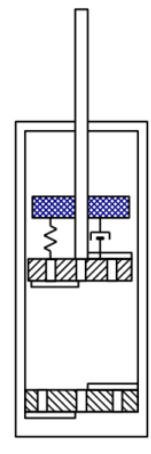

b)

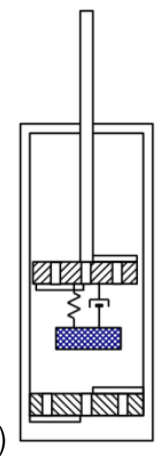

d)

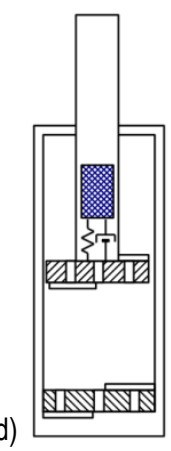

Fig. 5. Tuned mass damper locations: a) external, b,c,d) internal

In a real world application tuned mass dampers could be located outside the damper and at the top mount assembly as in Fig. 5a; or, alternatively, inside the damper at the piston (see Fig. $5 b$ and $5 c$ ). Locating the assembly inside the piston rod can be envisioned, too, as in Fig. 5 d.

To include the tuned mass damper dynamics the following relationship can be deduced:

$m_{5}\left(\ddot{x}_{5}-\ddot{x}_{p r}\right)+c_{5} \dot{x}_{5}+k_{5} x_{5}=0$,

where: $m_{5}-$ TMD mass, $k_{5}$ - spring stiffness, $c_{5}=2 \zeta \sqrt{k_{5} m_{5}}-$ TMD damping, $\zeta$ is dimensionless damping coefficient. 


\section{sciendo}

Marian Sikora

Modeling and Operational Analysis of an Automotive Shock Absorber with a Tuned Mass Damper

Finally, the piston rod motion can be described by the following equation:

$m_{p r} \ddot{x}_{p r}+c_{p r} \dot{x}_{p r}+k_{p r} x_{p r}=F_{D}$

$\left\{F_{D}=A_{c} P_{\text {comp }}-A_{r} P_{\text {reb }}+F_{\text {friction }}\right.$

where: $F_{D}$ is the output damping force. Finally, the friction force at the cylinder-piston interface and the rod guide-rod interface is specifically modelled using the Bingham-Weng friction model (Wang, 2011):

$\mathrm{F}_{\text {friction }}=c_{0}\left(\dot{x}_{p r}-\dot{x}_{e}\right)+\frac{2}{\pi} f_{c} \arctan \left\{k_{H}\left[\dot{x}_{p r}-\dot{x}_{e}-\right.\right.$

$\left.\left.x_{H} \operatorname{sgn}\left(\ddot{x}_{p r}-\ddot{x}_{e}\right)\right]\right\}$

where: $c_{0}$ - friction component damping coefficient, $f_{c}$ - frictional force, and $k_{H}, X_{H}$ refer to the shape coefficient and the hysteretic velocity, respectively. In particular, based on equations $3,8,9,10$, and 11 the behavior of the damper can be studied by solving the system of equations in MATLAB R2017b.

\section{Inputs}

In the paper the author considered damping level range presented in Fig. 6. All damping levels were chosen arbitrarily to create both linear and non-linear force-velocity characteristics. The figure shows the plot of the output force $F_{D}$ vs. the relative velocity $V_{\text {rel }}$ :

$v_{r e l}=\dot{x}_{p r}-\dot{x}_{e}$

In the figure rebound forces are negative and compression forces positive. The valves were effectively setup to yield Case 1) low compression and low rebound force, Case 2) high compression and low rebound force, Case 3) low compression and high rebound force, Case 4) high compression and rebound force.

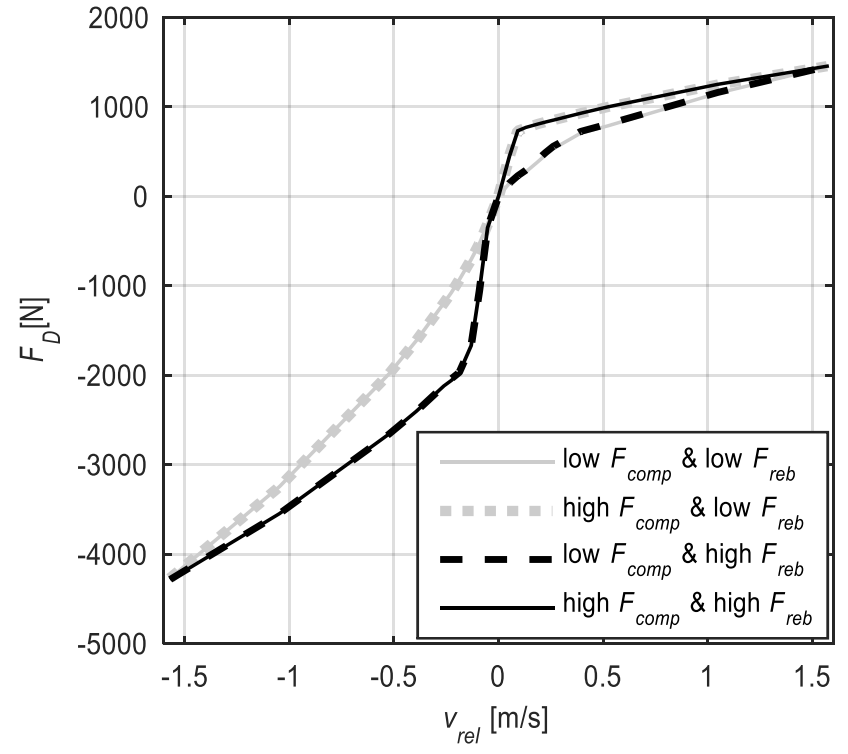

Fig. 6. Static force-velocity characteristics of the simulated damper configurations - Cases 1-4

In all of the examined cases the damping force at the piston velocity of $1.5 \mathrm{~m} / \mathrm{s}$ is identical; however, the behavior of the damper is adjusted at low and medium speeds. At the reference velocity of $0.188 \mathrm{~m} / \mathrm{s}$ the (high) rebound force is double of the (low) rebound force output. For example, the compression force is around $400 \mathrm{~N}$ in the low force scenario and $807 \mathrm{~N}$ in the high one. The rebound force is around $935 \mathrm{~N}$ in the low force case and grows to around $1973 \mathrm{~N}$ in the high force scenario. The damper model was setup with the data revealed in Tab. 1. The tuned mass damper model was setup with the following parameter set: $m_{5}=\left[\begin{array}{llll}10 & 20 & 40 & 80\end{array}\right] \mathrm{g}$ and $\zeta=\left[\begin{array}{llll}0 & 0.1 & 0.3 & 1\end{array}\right]$. The stiffnes $k_{5}$ and the damping coefficient $c_{5}$ was calculated assuming the natural frequency of the simulated damper system without the tuned mass damper component within the range from $491 \mathrm{~Hz}$ to $511 \mathrm{~Hz}$.

Tab. 1. Damper model parameters. The value in the brackets refers to the specific scenarios $-1,2,3,4$, respectively

\begin{tabular}{|c|c|}
\hline Parameter & Value \\
\hline Piston diameter $D[\mathrm{~mm}]$ & 32.016 \\
\hline Rod diameter $d[\mathrm{~mm}]$ & 13.946 \\
\hline Damper length $L_{0}[\mathrm{~mm}]$ & 174.5 \\
\hline Gass pressure $P_{g 0}[\mathrm{~Pa}]$ & $4 \cdot 10^{5}$ \\
\hline Oil density $\rho\left[\mathrm{g} / \mathrm{cm}^{3}\right]$ & 0.83 \\
\hline Oil compressibility $\beta\left[\mathrm{MPa}^{-1}\right]$ & $3.0360 \mathrm{e}-03$ \\
\hline Oil viscosity $\mu\left[\mathrm{Pa}^{*} \mathrm{~s}\right]$ & 0.04 \\
\hline Tube wall thickness $s[\mathrm{~mm}]$ & 0.992 \\
\hline Steel Young modulus $E[\mathrm{GPa}]$ & 210 \\
\hline Compression stack mass $m_{1}[\mathrm{~g}]$ & 1.463 \\
\hline Intake disc mass $m_{2}[\mathrm{~g}]$ & 1.538 \\
\hline Rebound stack mass $m_{3}[\mathrm{~g}]$ & 1.842 \\
\hline Piston compression stack mass $m_{4}[\mathrm{~g}]$ & 1.998 \\
\hline Compression stack stiffness $k_{1}[\mathrm{~N} / \mathrm{mm}]$ & $\begin{array}{r}\left(1.1902 \cdot 10^{4}, 2.2889 \cdot 10^{3}\right. \\
\left.1.1902 \cdot 10^{4}, 2.2889 \cdot 10^{3}\right)\end{array}$ \\
\hline Intake disc stiffness $k_{2}[\mathrm{~N} / \mathrm{mm}]$ & 9.4396 \\
\hline Rebound stack stiffness $k_{3}[\mathrm{~N} / \mathrm{mm}]$ & $\begin{array}{r}\left(6.1269 \cdot 10^{3}, 6.1269 \cdot 10^{3},\right. \\
\left.3.9212 \cdot 10^{3}, 3.9212 \cdot 10^{3}\right) \\
\end{array}$ \\
\hline $\begin{array}{l}\text { Piston compression stack stiffness } k_{4} \\
{[\mathrm{~N} / \mathrm{mm}]}\end{array}$ & $\begin{array}{l}\left(7.6317 \cdot 10^{2}, 8.9784 \cdot 10^{2}\right. \\
\left.7.6317 \cdot 10^{2}, 8.9784 \cdot 10^{2}\right)\end{array}$ \\
\hline $\begin{array}{l}\text { Compression stack damping coefficent } c_{1} \\
{[\mathrm{Ns} / \mathrm{mm}]}\end{array}$ & $\begin{array}{r}\left(2.3805 \cdot 10^{1}, 4.5779\right. \\
\left.2.3805 \cdot 10^{1}, 4.5779\right)\end{array}$ \\
\hline Intake disc damping coefficent $\mathrm{C}_{2}[\mathrm{Ns} / \mathrm{mm}]$ & $9.4396 \cdot 10^{-3}$ \\
\hline $\begin{array}{l}\text { Rebound stack damping coefficent } c_{3} \\
{[\mathrm{Ns} / \mathrm{mm}]}\end{array}$ & $\begin{array}{r}\left(1.2254 \cdot 10^{1}, 1.2254 \cdot 10^{1}\right. \\
7.8424,7.8424) \\
\end{array}$ \\
\hline $\begin{array}{l}\text { Piston compression stack damping } \\
\text { coefficent } c_{4}[\mathrm{Ns} / \mathrm{mm}]\end{array}$ & $\begin{array}{r}(1.5263,1.7957,1.5263, \\
1.7957) \\
\end{array}$ \\
\hline Preload force of comp. stack $F_{s p 1}[\mathrm{~N}]$ & $(667,220,667,220)$ \\
\hline Preload force of intake disc $F_{s p 2}[\mathrm{~N}]$ & 0.19 \\
\hline Preload force of rebound stack $F_{s p 3}[\mathrm{~N}]$ & $(92,92,599,599)$ \\
\hline $\begin{array}{l}\text { Preload force of piston compression stack } \\
F_{s p 4}[\mathrm{~N}]\end{array}$ & $(9.16,163,9.16,163)$ \\
\hline $\begin{array}{l}\text { Piston comp. stack momentum force coeff. } \\
C_{f 1}\end{array}$ & 0.9 \\
\hline Intake disc momentum force coeff. $C_{f 2}$ & 0.85 \\
\hline $\begin{array}{llll}\text { Piston reb. stack momentum force } \\
\text { coefficient } C_{P_{3}}\end{array}$ & 0.9 \\
\hline $\begin{array}{l}\text { Piston comp. stack momentum force } \\
\text { coefficient } C_{f 4}\end{array}$ & 0.85 \\
\hline $\begin{array}{l}\text { Inlet cross-section area (comp. stack) } A_{i n 1} \\
{\left[\mathrm{~mm}^{2}\right]}\end{array}$ & 6.8094 \\
\hline $\begin{array}{l}\text { Inlet cross-section area } A_{\text {in2 }} \text { of intake disc } \\
{\left[\mathrm{mm}^{2}\right]}\end{array}$ & $1.1200 \cdot 10^{2}$ \\
\hline
\end{tabular}




\begin{tabular}{|c|c|}
\hline $\begin{array}{l}\text { Inlet cross-section area } A_{\text {in3 }} \text { (reb. stack) } \\
{\left[\mathrm{mm}^{2}\right]}\end{array}$ & $2.2902 \cdot 10^{1}$ \\
\hline $\begin{array}{l}\text { Inlet cross-section area } A_{i n 4} \text { (piston comp. } \\
\text { stack) }\left[\mathrm{mm}^{2}\right]\end{array}$ & $7.5752 \cdot 10^{1}$ \\
\hline Hydraulic radius (comp. stack) $R_{1}[\mathrm{~mm}]$ & 7.9 \\
\hline Hydraulic radius (intake disc) $R_{2}[\mathrm{~mm}]$ & 8.9 \\
\hline Hydraulic radius (rebound stack) $R_{3}[\mathrm{~mm}]$ & 8.6 \\
\hline $\begin{array}{l}\text { Hydraulic radius (piston comp. stack) } R_{4} \\
\text { [mm] }\end{array}$ & 7.8 \\
\hline Geometrical factor (compression stack) $X_{A 1}$ & 1.0178 \\
\hline Geometrical factor (intake disc) $X_{A 2}$ & 1.0532 \\
\hline Geometrical factor (reb. stack) $X_{A 3}$ & 1.0699 \\
\hline Geometrical factor (piston comp. stack) $X_{A 4}$ & 1.1884 \\
\hline Valve seat stiffness $k_{c}[\mathrm{~N} / \mathrm{mm}]$ & $1 \cdot 10^{6}$ \\
\hline Piston \& rod mass $m_{p r}[\mathrm{~g}]$ & 348.1 \\
\hline Top mount damping $C_{p r}[\mathrm{Ns} / \mathrm{mm}]$ & 0.080 \\
\hline Top mount stiffness $K_{p r}[\mathrm{~N} / \mathrm{mm}]$ & $1.3 \cdot 10^{3}$ \\
\hline Clearance (piston rod-rod guide) $b_{r}[\mathrm{~mm}]$ & 0.028 \\
\hline $\begin{array}{l}\text { Leakage channel length (piston rod-rod } \\
\text { guide) } I_{r}[\mathrm{~mm}]\end{array}$ & 9.9 \\
\hline Clearance (piston-cylinder) $b_{p}[\mathrm{~mm}]$ & 0.0205 \\
\hline $\begin{array}{l}\text { Leakage channel length (piston-cylinder) } l_{p} \\
{[\mathrm{~mm}]}\end{array}$ & 9.35 \\
\hline $\begin{array}{l}\text { Comp. stack dynamic discharge coefficient } \\
C_{D 1}\end{array}$ & 0.5 \\
\hline $\begin{array}{l}\text { Intake disc dynamic discharge coefficient } \\
C_{D 2}\end{array}$ & 0.9 \\
\hline $\begin{array}{l}\text { Base valve orifice dynamic discharge } \\
\text { coefficient } C_{D n c}\end{array}$ & 0.5 \\
\hline Base valve orifice area $A_{n c}\left[\mathrm{~mm}^{2}\right]$ & $2.73 \cdot 10^{-1}$ \\
\hline $\begin{array}{l}\text { Reb. stack dynamic discharge coefficient } \\
C_{D 3}\end{array}$ & 0.5 \\
\hline $\begin{array}{l}\text { Piston comp. stack dynamic discharge } \\
\text { coefficient } C_{D 4}\end{array}$ & 0.9 \\
\hline $\begin{array}{l}\text { Piston orifice dynamic discharge coefficient } \\
C_{D n r}\end{array}$ & 0.9 \\
\hline Piston orifice area $A_{n r}\left[\mathrm{~mm}^{2}\right]$ & 1.0440 \\
\hline
\end{tabular}

\section{Results}

In this section the author highlights the simulation results for the two selected damper settings: Case 1) low compression and

a)

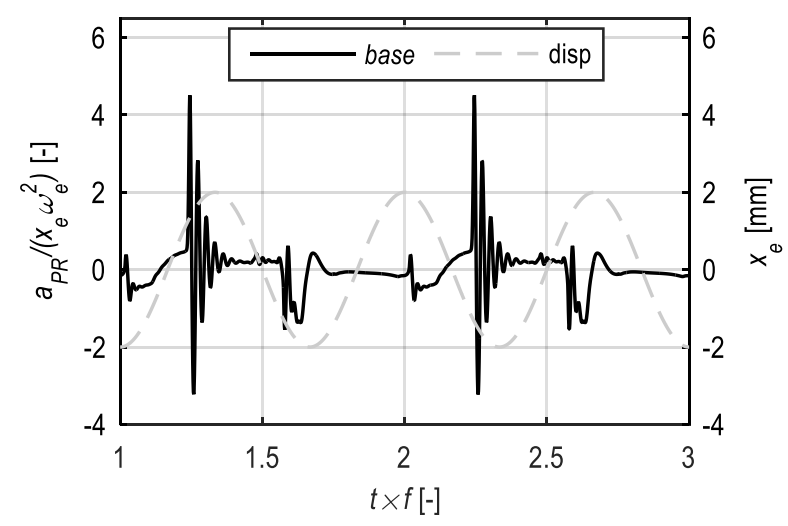

low rebound force, Case 4) high compression and high rebound force. The first part of the material concerns a double-tube damper subjected to oscillatory (sinusoidal) displacement inputs. The contents include presentation of the numerical results followed by the so-called sensitivity analysis.

\subsection{Response to oscillatory inputs}

The simulation results are presented in Figs. 7-8. The data reveal the response of the damper subjected to oscillatory displacement inputs of the amplitude equal to $2 \mathrm{~mm}$ and the input frequency $15 \mathrm{~Hz}$. This frequency is the natural frequency of unsprung masses of automotive suspension systems, and is often used in laboratory tests for examining the dynamic behavior of the dampers. The illustrations show the output of the model in terms of the input displacement waveform, the output piston rod acceleration time history and FFT (Fast Fourier Transform) spectra of the acceleration signal. The sampling frequency of the rod acceleration is $12.8 \mathrm{kHz}$ and the FFT is calculated based on oscillations after the compression-to-rebound transition. The FFT window is rectangular and $20 \mathrm{~ms}$ long. In particular, Fig. 7 reveals the Case 1 data, and the Case 4 output is shown in Fig. 8. In either scenario the simulations involved the model response at various levels of the tuned mass damper component damping factor $\zeta$ and its mass $m_{5}$, respectively. The illustrations $7 a$ and 8 a reveal the output of specific configurations w/o the tuned mass damper component. In each case the acceleration time history reveals oscillations following the stroker's motion reversals. The oscillations magnitude is different during the transition from compression to rebound than from rebound to compression. Specifically, Case 4 results in a nearly doubled acceleration output compared to the damper configuration in Fig. 7 (Case 1).

The performance of both damper settings were simulated using four mass levels $m_{5}$ and four different combinations of the damping coefficients $\zeta$, thus yielding 16 data sets (plotted as normalized frequency spectra) shown in Figs. 7c-7f (Case 1) and Figs. 8c-8f (Case 4). The observations imply the tuned damper mass is a basic tuning parameter. It defines the amount of energy transferred from the piston rod assembly to the component. The tuned damper mass significantly influences the anti-resonance zone. For the mass $m_{5}=10 \mathrm{~g}$ the anti-resonance zone width is equal to 0.2 , and it increases as the mass is added to the tuned mass damper. For the mass $m_{5}=80 \mathrm{~g}$ the anti-resonance zone (valley) width is approximately 0.48 .

b)

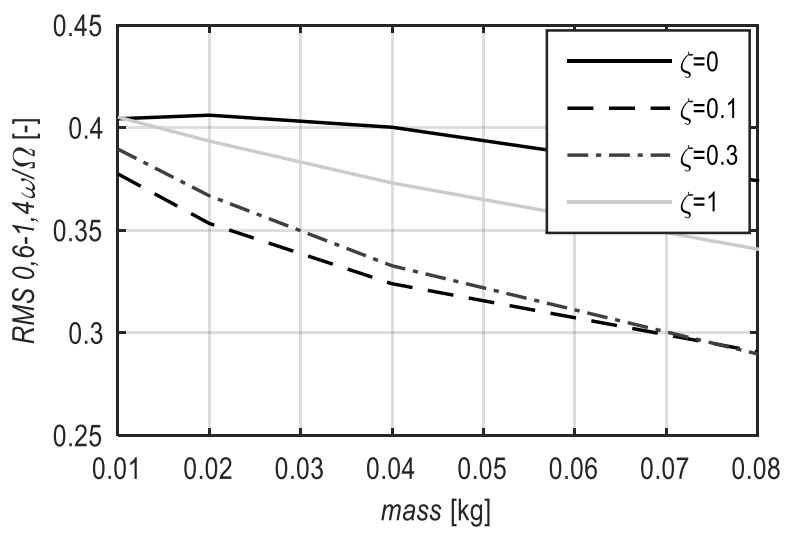


Modeling and Operational Analysis of an Automotive Shock Absorber with a Tuned Mass Damper

c)

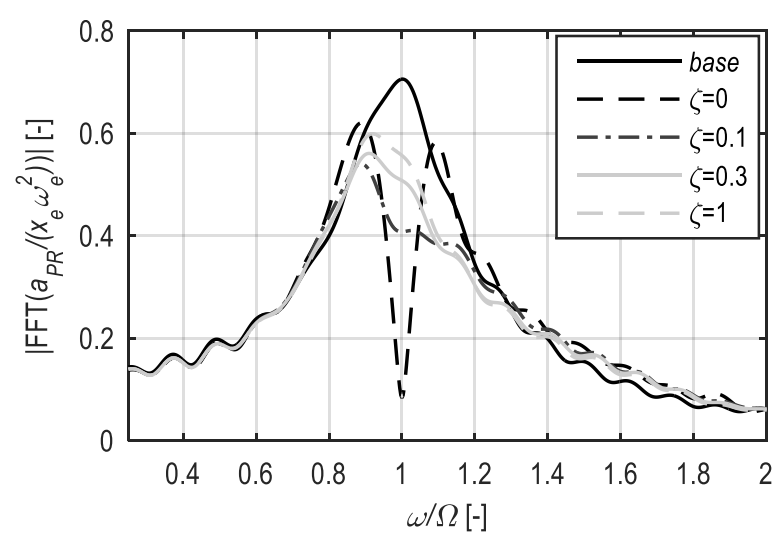

e)

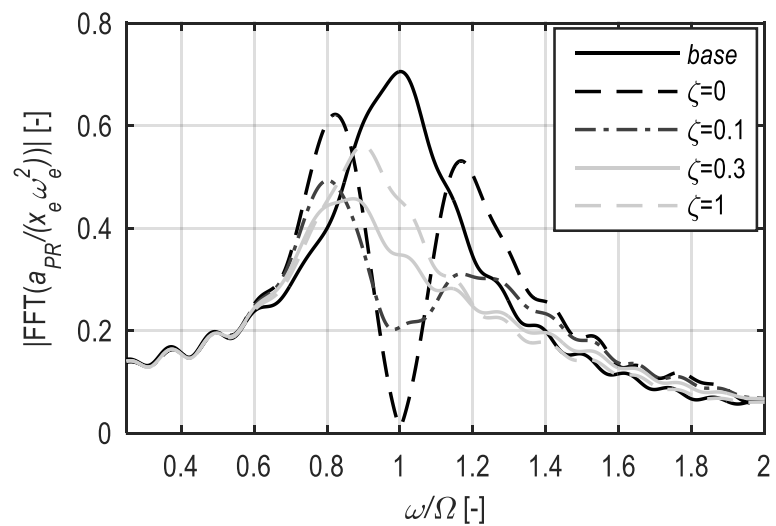

d)

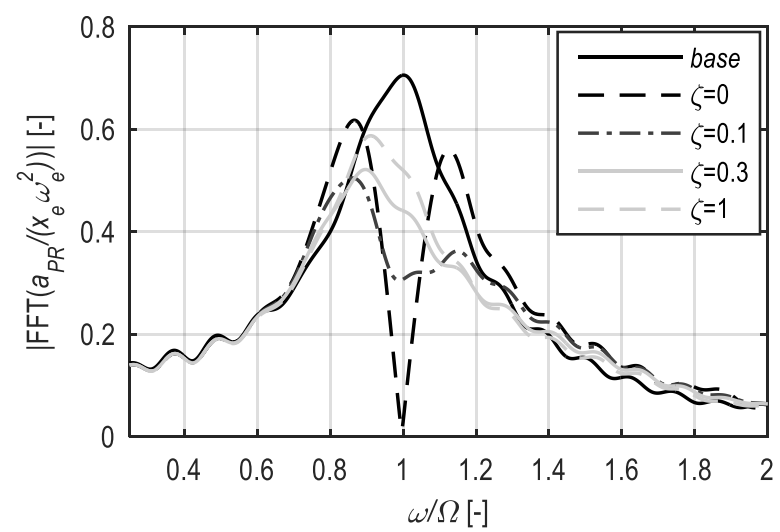

f)

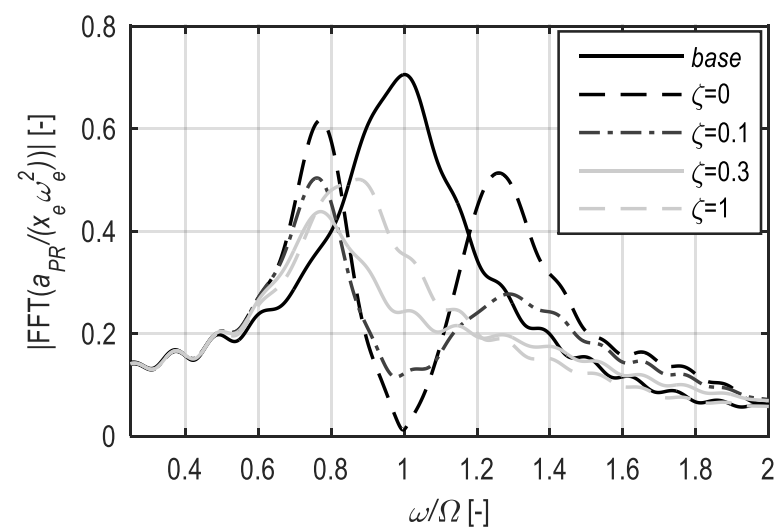

Fig. 7. Case 1: damper with low compression and low rebound force a) piston rod acceleration of the reference damper without the TMD component; b) quality factor of the damper with the tuned mass damper versus mass and damping coeffiecient; piston rod acceleration FFT of the damper with the tuned mass damper, the additional mass is respectively: c) $\left.m_{5}=0,01 \mathrm{~kg} ; \mathrm{d}\right) m_{5}=0,02 \mathrm{~kg} ; \mathrm{e}$ ) $m_{5}=0,04 \mathrm{~kg}$; and f) $m_{5}=0,08 \mathrm{~kg}$

a)

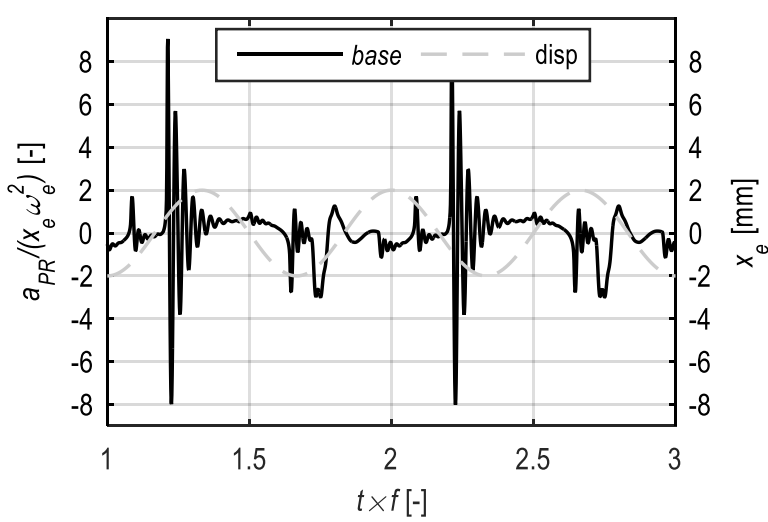

c)

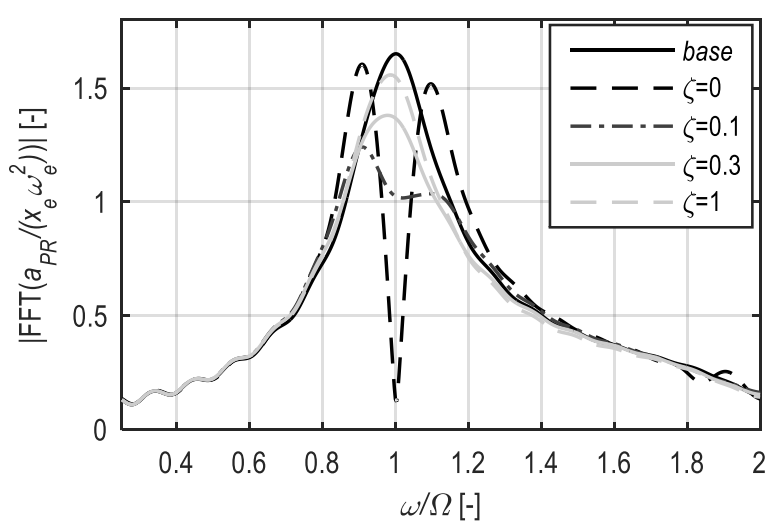

b)

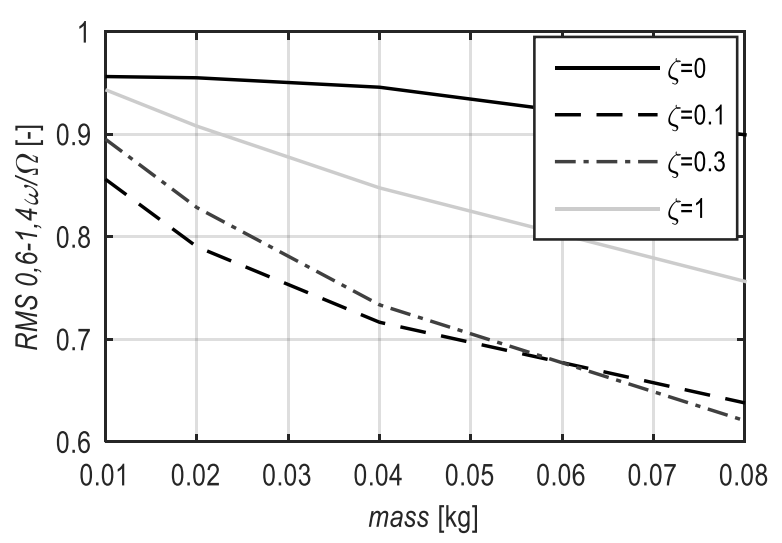

d)

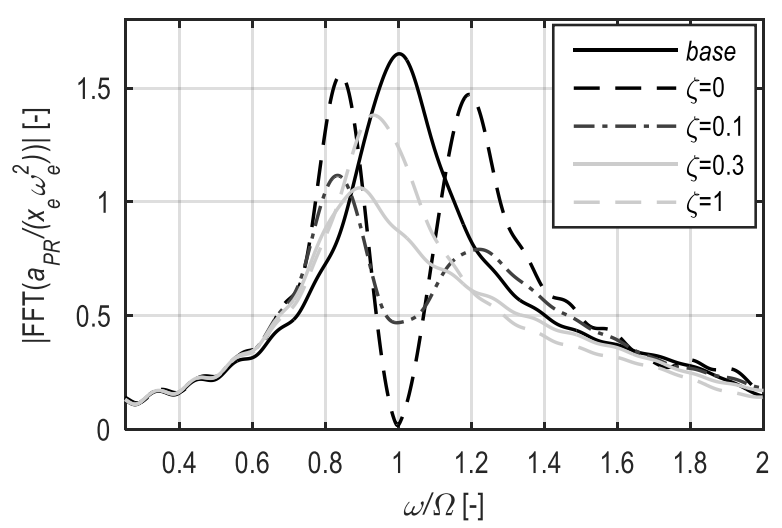


e)

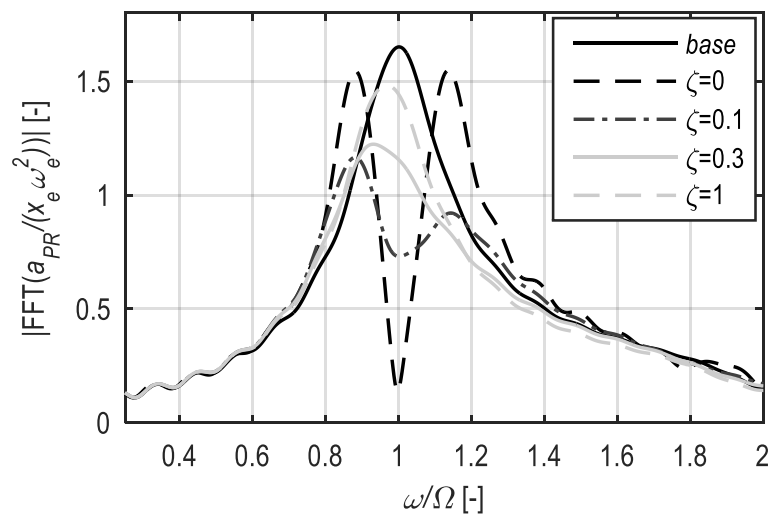

f)

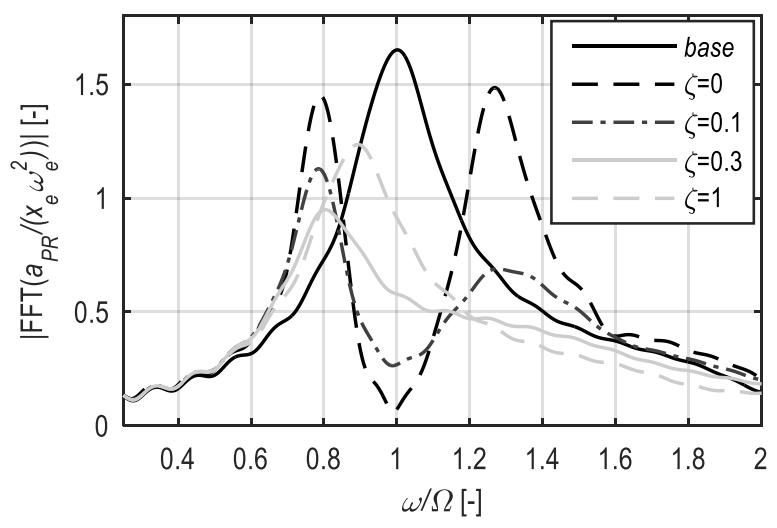

Fig. 8. Case 4: damper with high compression and high rebound force a) piston rod acceleration of the reference damper without the TMD component; b) quality factor of damper with the TMD part versus mass and damping coeffiecient; piston rod acceleration FFT of the damper with the TMD component, the additional mass is respectively: c) $m_{5}=0,01 \mathrm{~kg}$; d) $m_{5}=0,02 \mathrm{~kg}$; e) $m_{5}=0,04 \mathrm{~kg}$; and f) $m_{5}=0,08 \mathrm{~kg}$

The damping coefficient $\zeta$ also affects the vibrations amplitude. A system or a component that would allow controlling the tuned mass damper damping level may be difficult to achieve in practical applications, though. However, the results can be spectacular. In the zero damping case the output data show two distinct peaks of lower amplitude when compared against the nonoutput of a damper without the tuned mass damper. Increasing the damping level affects the damper's performance. The damping impact is twofold. First, it reduces the anti-resonance (valley) zone depth. Second, it reduces the amplitude of the peaks in the presented frequency spectra. It should be noted that the higher frequency peak is reduced more than the one at the lower frequency. At $\zeta=0.3$ that anti-resonance zone is effectively eliminated. At the highest damping level $\zeta=1$ the level of vibrations is higher than at lower damping levels.

a)

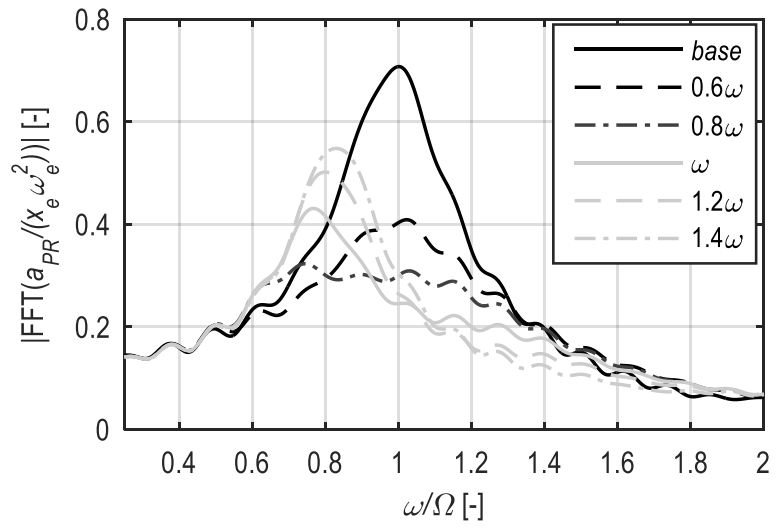

\subsection{Sensitivity Study}

Next, Figs. 9-12 present the sensitivity study results computed for the four damper configurations and using the following tuned mass damper component parameters: $m_{5}=80 \mathrm{~g}$ and damping $\zeta=0.3$. Apparently, the setting yields optimum results. Specifically, the Case 1 setting was illustrated in Fig. 9, Case 2 in Fig. 10, Case 3 in Fig. 11, and the output of Case 4 is highlighted in Fig. 12. On brief inspection of the figures it can be concluded that the damper system is highly tolerant on the tuned mass damper mass and stiffness variations; variation by $+/-40 \%$ still allows for an acceptable suppression of the piston rod vibration.

The performance of a specific setting can be estimated using the so-called quality factor. The quality factor is based on the acceleration root mean square (RMS) value calculated within the (normalized) frequency range from 0.6 to 1.4 . The calculated data show that the optimum results can be obtained with the tuned mass damper mass of $80 \mathrm{~g}$ and the damping level $\zeta=0.3$. In both case the improvement is over $30 \%$ (Case $1-36.5 \%$, Case $4-$ $36.9 \%$ ).

b)

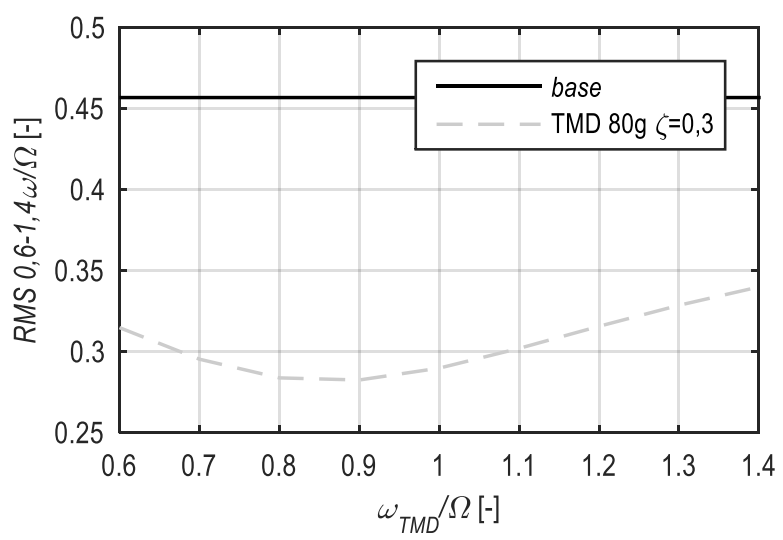

Fig. 9. Case 1: a) FFT of piston rod acceleration versus tuned mass damper eigenfrequency variation; b) quality factor 
a)

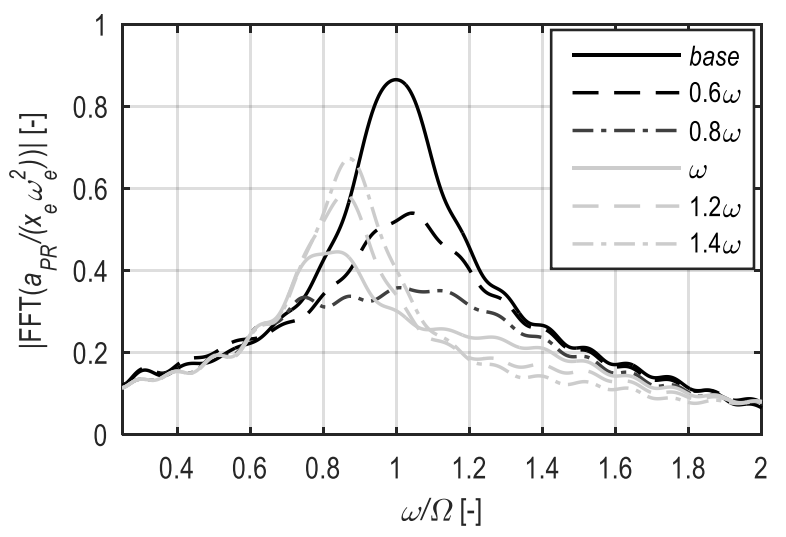

b)

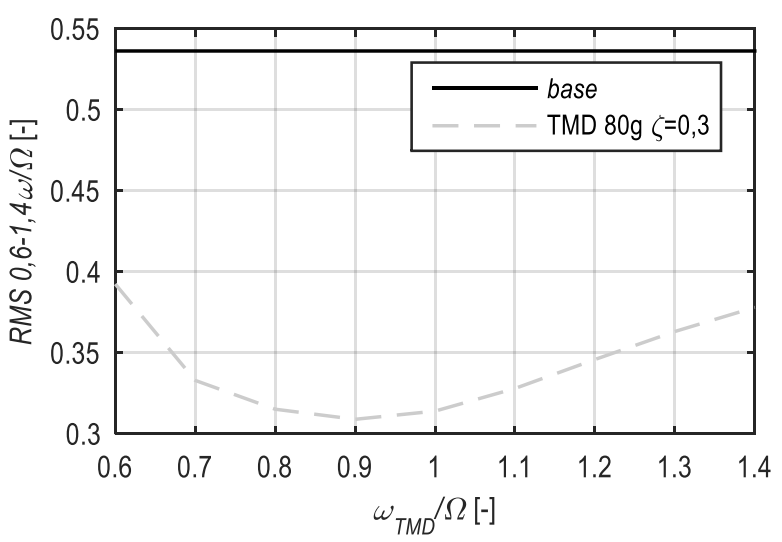

Fig. 10. Case 2: a) FFT of piston rod acceleration versus tuned mass damper eigenfrequency variation; b) quality factor

a)

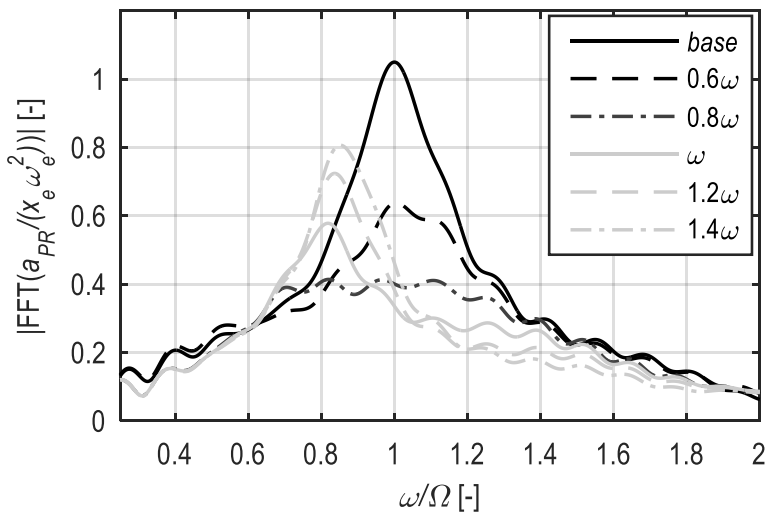

b)

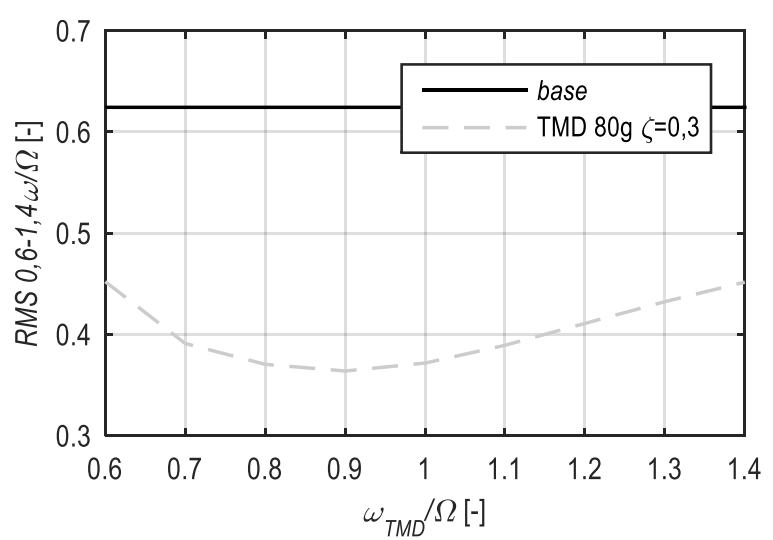

Fig. 11. Case 3: a) FFT of piston rod acceleration versus tuned mass damper eigenfrequency variation; b) quality factor

a)

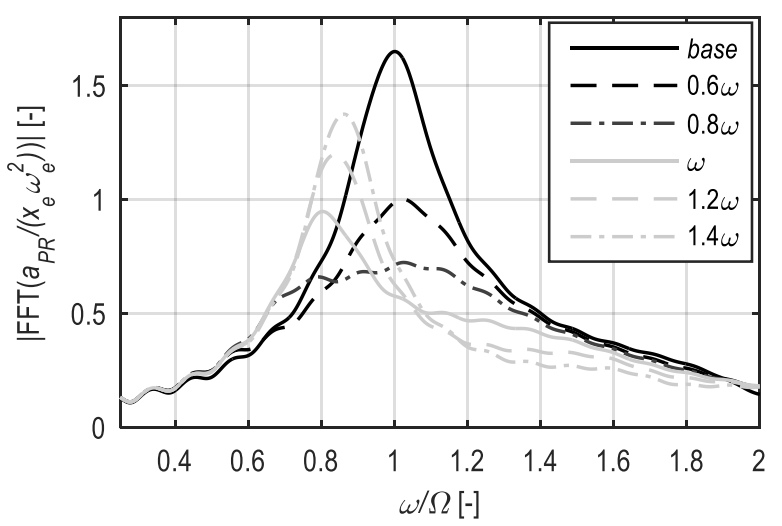

b)

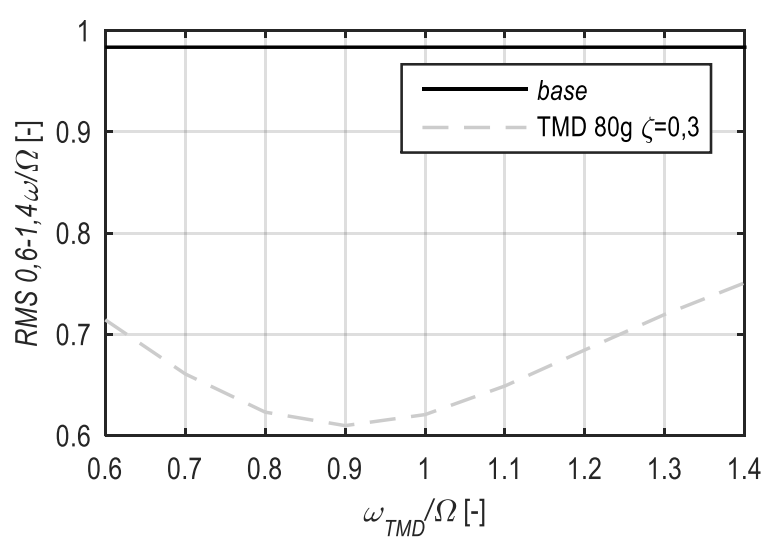

Fig. 12. Case 4: a) FFT of piston rod acceleration versus tuned mass damper eigenfrequency variation; b) quality factor

In addition to that, the simulations reveal that tuning the tuned mass damper for lower frequencies is beneficial. The optimum results are approximately at the frequency $0.9 \omega_{T M D} / \Omega$. In particular, the Case 1 gain is $38.2 \%$, and $38 \%$ for the Case 4 input. For the remaining cases, the gain was $42.4 \%$ for the Case 2 , and $41.7 \%$ for the Case 3 data.

\section{CONCLUSION}

The purpose of this study was to develop a math-based model of a twin-tube damper with a tuned mass damper concept; the model is yet to be verified experimentally. To summarize, the model was subjected to oscillatory displacement mediumfrequency inputs in a manner resembling testing conditions in a real lab. The obtained numerical data reveal that the concept may be an efficient way of shaping the dynamic characteristics of a hydraulic damper. Observations of the simulated data show that improved characteristics can be achieved with no negative impact on the steady-state performance (force-velocity) characteristics. The concept shows that stable operation and robustness can be achieved with a tuned mass damper regardless of the tuned mass damper characteristics modification/parameter fluctuations. 


\section{REFERENCES}

1. Bayer H. (1993), Vibration damping supporting strut for a motor vehicle, patent US5263560

2. Benaziz M., Nacivet S., Deak J., Thouverez F. (2013), Double tube shock absorber model for noise and vibration analysis, SAE International, 6(2), 1177-1185.

3. Czop P., Sławik D. (2011) A high-frequency first-principle model of a shock absorber and servo-hydraulic tester, Mechanical Systems and Signal Processing, 25/6 1937-1955.

4. Czop P., Sławik D., Śliwa P., Wszołek G. (2009), Simplified and advanced models of a valve system used in shock absorbers, Journal of Achievements in Materials and Manufacturing Engineering, 33(2), 173-180

5. Dixon J.C. (2007), The shock absorber handbook, Professional Engineering Publishing Ltd and John Wiley and Sons, Ltd.

6. Duym S., Steins R., Reybrouck K. (1997), Evaluation of shock absorber models, Vehicle System Dynamics, International Journal of Vehicle Mechanics and Mobility, 27(2), 109-127

7. Ezzat Khalifa H., Xin L. (1998), Analysis of stiction effect on the dynamics of compressor suction valve, The International Compressor Engineering Conference, Prude University.

8. Farjoud A., Ahmadian M., Craft M., Burke W. (2012), Nonlinear modeling and experimental characterization of hydraulic dampers: effects of shim stack and orifice parameters on damper performance, Nonlinear Dynamics, 67 1437-1456
9. Frahm H. (1911) Device for damping vibration of bodies, patent US989958A.

10. Gehrlich T., Horn G., Keller H.H., Schilling G., Lange D., Wagner E. (1992), Vehicle suspension, patent GB2258903.

11. Kohlmeier H.H. (1992), Vibration absorber, patent EP0531766.

12. Kruse A. (2002) Characterizing and reducing structural noises of vehicle shock absorber system, SAE Technical Report 2002-01-1234

13. Kruse A. (2008), Analysis of dynamic pressure build-up in twin-tube vehicle shock absorbers with respect to vehicle acoustics, SAE International, Vehicle Dynamics Expo 2008, Stuttgart,

14. Lang H.H. (1977), A study of the characteristics of automotive hydraulic dampers at high stroking frequencies, The University of Michigan.

15. Shimizu K., Hiruma M. (1987), Frequency and stroke depending type damper, patent JPS62106138

16. Trintignac C., Trema D. (1982), Shock absorber upper fastening, patent FR2535259

17. Tsuruta M., Kawabe H., Kobayashi Y., Matsumoto S., Yoshida M. (1999), Vehicle suspension system, patent EP0992372

18. Wang D.H., Liao W.H. (2011), Magnetorheological fluid dampers: a review of parametric modeling, Smart materials and Structures, 20(2), 023001.

Acknowledgment: This study was carried out within the scope of the project no. POIR.01.02.00-00-0305/16 funded by the National Center for Research and Development (Poland). 